\title{
Multifocal ERG in ethambutol associated visual loss
}

\author{
R S Behbehani, E L Affel, R C Sergott, P J Savino
}

Br J Ophthalmol 2005;89:976-982. doi: 10.1136/bjo.2004.065656

\begin{abstract}
Aim: To determine the anatomical site and extent of electrophysiological dysfunction in patients with ethambutol associated visual loss.

Methods: A comparative case series. Four patients with ethambutol associated visual loss underwent multifocal electroretinography (mERG). Two patients had advanced visual loss while two had early signs of toxicity. The N1-PI, $\mathrm{N} 1, \mathrm{Pl}$ amplitudes, $\mathrm{N1}$, and $\mathrm{Pl}$ latencies were compared to 10 age and sex matched controls.

Results: $m E R G$ abnormalities were detected in the ethambutol treated patients. The N1 amplitude was significantly lower in the ethambutol treated patients than in the control group. Conclusion: Ethambutol is possibly toxic to the retina, and not only the optic nerve. The multifocal ERG may be of value to diagnose and monitor patients taking ethambutol.
\end{abstract}

E hambutol is commonly used for the treatment of tuberculosis and Mycobacterium avium complex (MAC) infections. It has been associated with optic neuropathy, $^{12}$ colour vision abnormalities, and visual field defects. $^{3-5}$ Ocular toxicity is dose and duration dependent with the incidence as high as $6 \%$ in patients receiving more than $15-25 \mathrm{mg} / \mathrm{kg} /$ day. $^{6}{ }^{7}$

We used multifocal electroretinography (mERG) to test four patients diagnosed with ethambutol ocular toxicity and compared them to normal age and sex matched control subjects. Our aim was to is investigate whether there is electrophysiological dysfunction at the level of photoreceptors and outer plexiform layer (outer retina). Ethambutol toxicity has so far been associated mainly with optic nerve damage (inner retina). ${ }^{128}$

\section{PATIENTS AND METHODS}

Multiple retinal areas were stimulated to record local retinal responses with the mERG technique using the Veris 4.8 software (Veris; Electro-Diagnostic Imaging, San Mateo, CA, USA). Fixation was carefully monitored throughout the test procedure. The fixation target was enlarged for subjects who had poor vision. Segments with large eye movements, losses of fixation, or blinks were discarded and re-recorded.

\section{Patient 1}

A 60 year old woman presented with complaints of "visual blurring" and "intolerance to bright lights" in both eyes a month after beginning ethambutol ( $13.65 \mathrm{mg} / \mathrm{kg}$ per day) for a recurrent pulmonary MAC infection.

Visual acuity was 20/25 in each eye. She had normal colour vision, and her anterior segment examination was unremarkable. Both pupils were sluggish to direct light stimulation with no relative afferent pupillary defect (RAPD). Fundus examination showed normal discs and maculae. Using the Humphrey 10-2 program, an early central defect was found in the right eye and a centrocaecal defect in the left eye. The
mERG waveforms were decreased in amplitude in both eyes to pattern stimuli (fig 1)

Ethambutol was discontinued and 6 months later the visual acuity was 20/20 in each eye, her colour vision was full and her visual fields were normal. Repeated mERG showed a persistent decrease in amplitudes in both eyes with delayed latencies to pattern stimuli (fig 2).

\section{Patient 2}

An 80 year old woman presented with decreased vision in both eyes for 3 weeks. She was being treated with ethambutol ( $15 \mathrm{mg} / \mathrm{kg}$ per day) for 7 months for a pulmonary MAC infection. Visual acuity was counting fingers in each eye. Examination of the anterior segment was normal. The pupillary light reactions were sluggish bilaterally with a left RAPD. Visual field testing by confrontation showed dense central scotomas bilaterally; visual acuity was too poor for formal visual field testing. She had pale optic nerve heads bilaterally. Computed tomography (CT) and magnetic resonance imaging (MRI) of the brain and orbits were normal.

Multifocal ERG results showed diffuse reduction in the amplitudes, especially in the central area (fig 3) She was seen 4 months after discontinuation of ethambutol and her vision had improved to 20/100 right eye and 20/40 left eye. Repeat mERG still showed decreased amplitudes, and diminished foveal peaks. There was no appreciable change compared to the first mERG (fig 4).

\section{Patient 3}

A 66 year old man who was diagnosed 5 months earlier with MAC pulmonary infection and was started on ethambutol ( $15 \mathrm{mg} / \mathrm{kg}$ per day) presented with a complaint of "objects looking too bright" and "difficulty of adjusting from bright to dim light conditions." Visual acuity was 20/30 in the right and 20/20 in the left eye. Colour vision was normal in both eyes. Slit lamp examination was unremarkable. The pupils were normal with no RAPD. Fundus examination showed normal discs and maculae. Automated static perimetry (Humphrey 24-2) was normal, but a using a Humphrey 10-2 program, there was one area of depression in the right eye. Full field ERG was normal in both eyes. mERG demonstrated decreased amplitudes and reduced foveal peaks in both eyes to pattern stimuli (fig 5).

\section{Patient 4}

A 75 year old woman noticed worsening of vision after undergoing cataract surgery in the left eye. She had been on ethambutol, isoniazid and rifampin for a pulmonary MAC infection. Visual acuity was counting fingers at 2 feet in the right and at 6 feet in the left eye. She identified only the test plates of the Ishihara pseudoisochromatic plates in each eye. Slit lamp examination was unremarkable. The pupils were

Abbreviations: $\mathrm{CT}$, computed tomography; ERG, electroretinography; MAC, Mycobacterium avium complex; mERG, multifocal electroretinography; MRI, magnetic resonance imaging; RAPD, relative afferent pupillary defect 
A Field view,

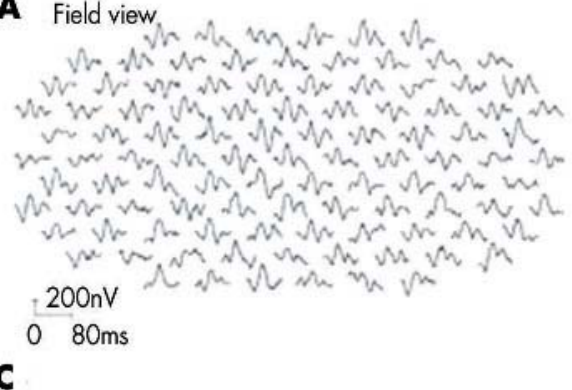

Total response:

$5.43 \mathrm{nV} / \operatorname{deg}^{2}$

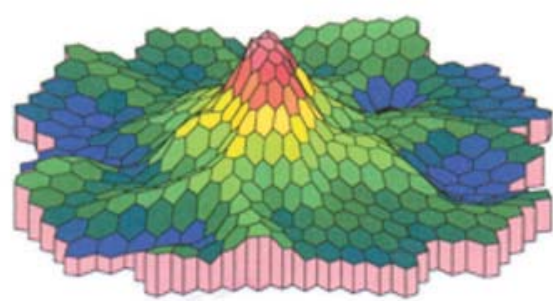

20

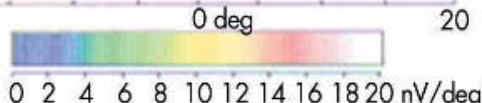

$024468101214161820 \mathrm{nV} / \mathrm{deg}^{2}$
B Field view

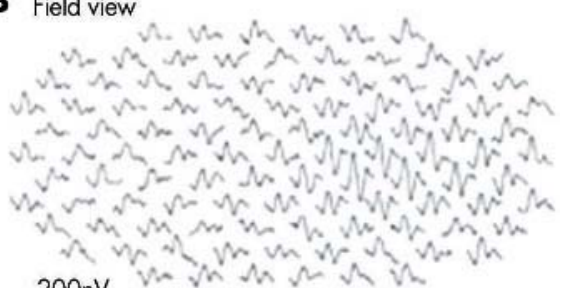

$200 \mathrm{nV}$

$0 \quad 80 \mathrm{~ms}$

D

Total response:

$5.86 \mathrm{nV} / \operatorname{deg}^{2}$

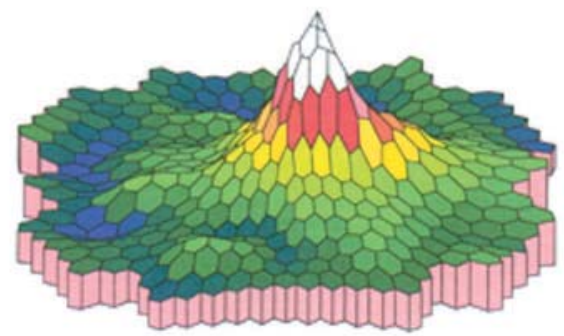

20

0 deg

20

$02468101214161820 \mathrm{nV} / \mathrm{deg}^{2}$

Figure 1 Trace arrays showing subnormal $m E R G$ with decreased amplitudes in the both eyes. In $(A)$ the right eye, and (B) the left eye, there are decreased amplitudes in the central area. The three dimensional

topography map shows blunted foveal peaks more in the right (C) than the left eye (D).

A

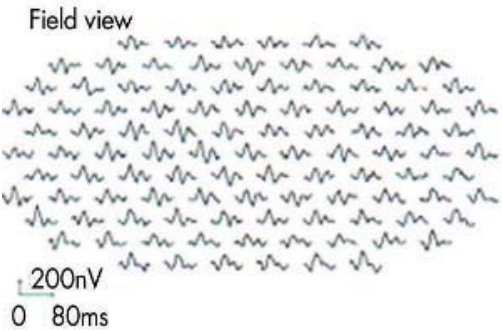

\section{C}

Total response:

$5.67 \mathrm{nV} / \mathrm{deg}^{2}$

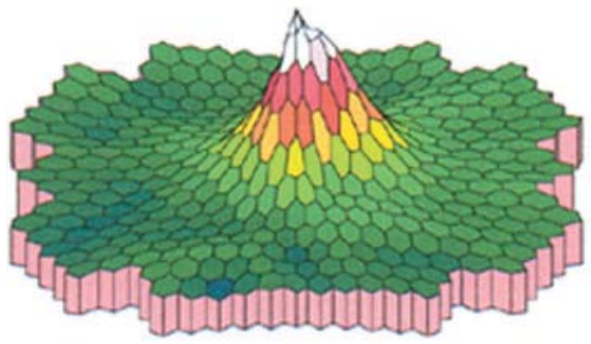

\section{B}

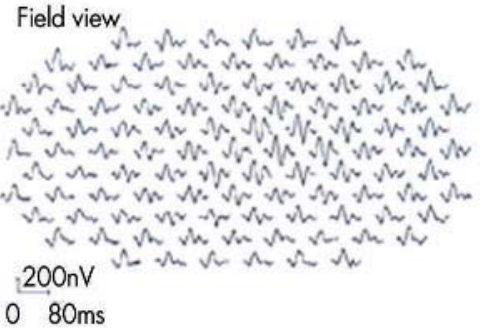

Total response: $6.29 \mathrm{nV} / \mathrm{deg}^{2}$

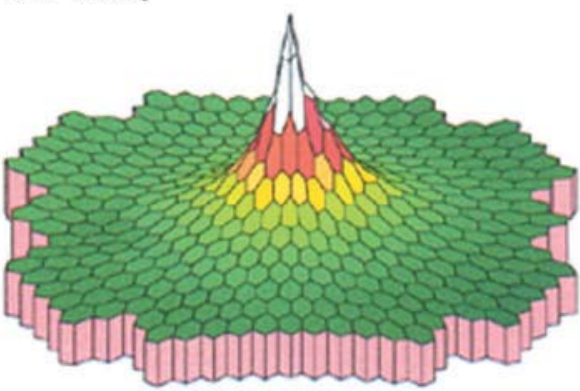

Figure 2 Trace arrays of multifocal ERG in (A) right and (B) left eyes. Amplitudes are diminished centrally more in the right eye than the left eye. The three dimensional topography map shows blunted foveal peaks more in the right (C) than the left eye (D). 
A

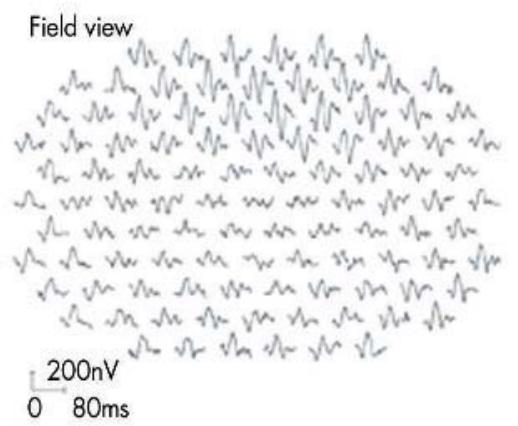

C

Total response:

$5.00 \mathrm{nV} / \mathrm{deg}^{2}$

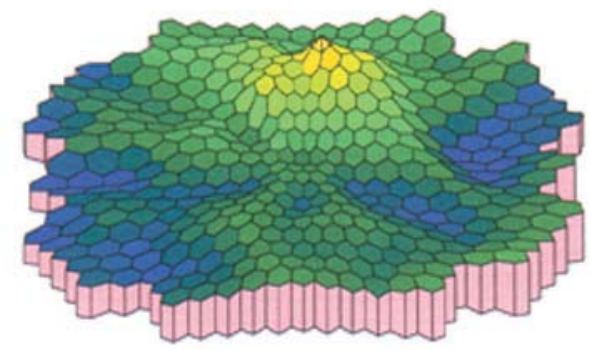

20

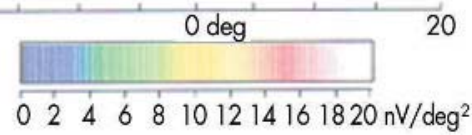

B

Field view

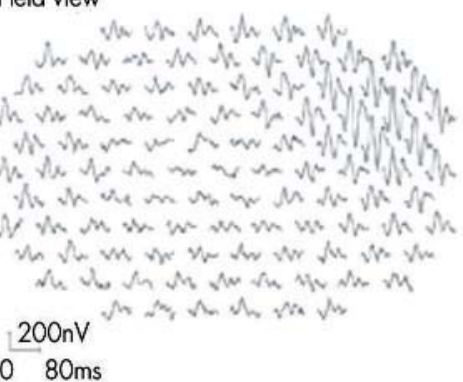

D

Total response: $5.00 \mathrm{nV} / \mathrm{deg}^{2}$
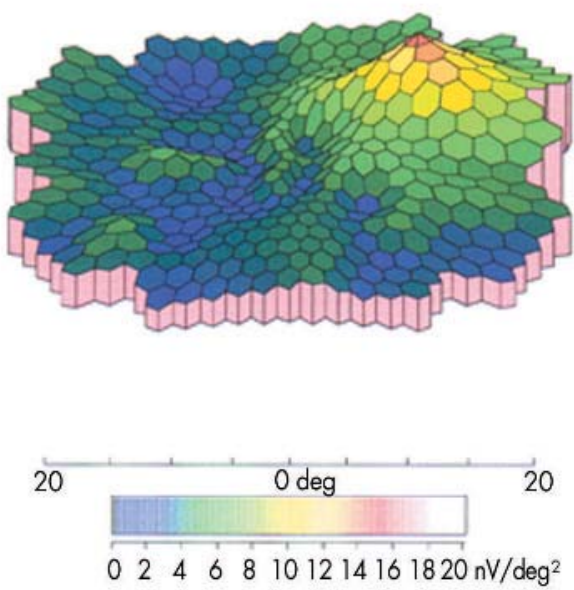

Figure 3 Trace arrays of (A) the right eye and (B) left eye show diminished amplitudes especially in the central areas. The topographic (three

dimensional) density plots show blunted foveal peaks in the right $(C)$ and the left (D) eye.

Table 2 Responses elicited from ring 2

\begin{tabular}{llllll}
\hline Category & $\begin{array}{l}\text { N1-P1 amplitude } \\
\text { (nv/deg }\end{array}$ & $\begin{array}{l}\text { N1 amplitude } \\
\left.\text { (nv/ } / \mathbf{d e g}^{2}\right)\end{array}$ & $\begin{array}{l}\text { P1 amplitude } \\
\text { (nv/deg) }\end{array}$ & $\begin{array}{l}\text { N1 latency } \\
\text { (ms) }\end{array}$ \\
\hline $\begin{array}{l}\text { Control } \\
\text { Patient }\end{array}$ & 24.445 & 8.6 & 15.78 & 9.06 & $\begin{array}{l}\text { P1 latency } \\
\text { (ms) }\end{array}$ \\
\hline
\end{tabular}


A

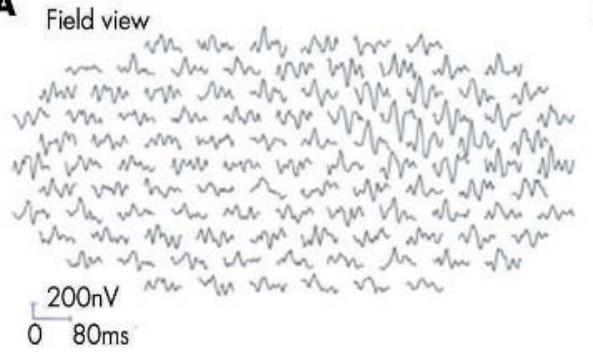

Total response:

$4.69 \mathrm{nV} / \mathrm{deg}^{2}$

C

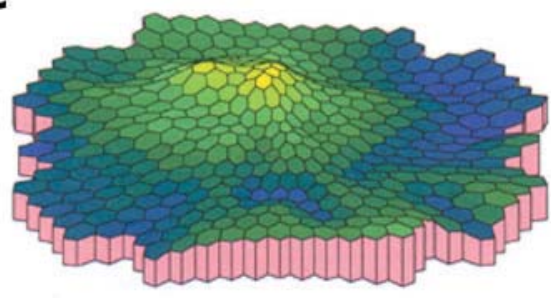

$20 \underbrace{20}_{0 \lcm{24} \quad 0 \operatorname{deg}}$
B Field view

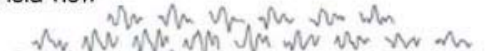

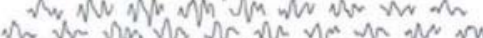

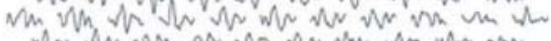

An the

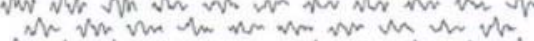

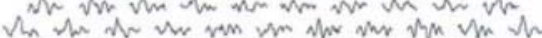

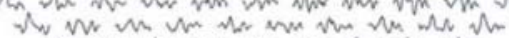

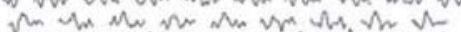

$200 \mathrm{nV}$

o $80 \mathrm{~ms}$

Total response:

$4.57 \mathrm{nV} / \mathrm{deg}^{2}$

\section{D}
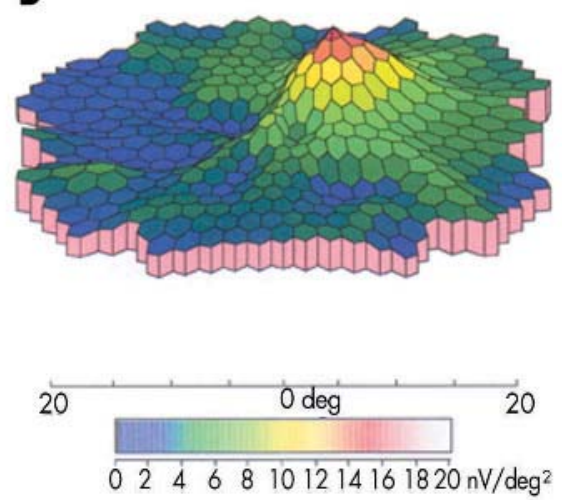

Figure 4 Trace arrays of $(A)$ the right eye and $(B)$ the left eye decreased amplitudes centrally. The topographic

(three dimensional) density plots show flattened foveal peaks in the right eye (C) and reduced peak in the left eye (D).
A Field view

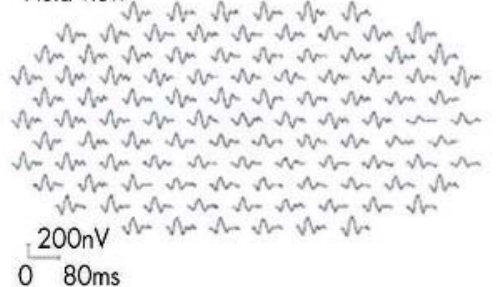

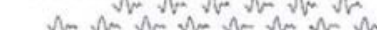
sen shen

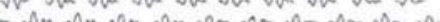
th the dis a the the the the $0 \quad 80 \mathrm{~ms}$
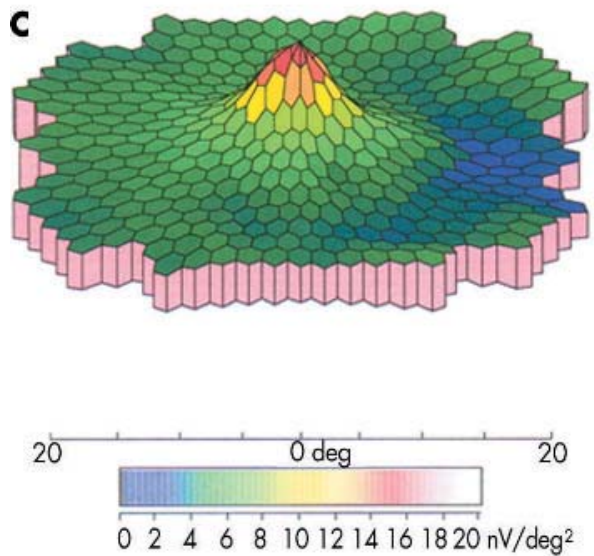

B Field view
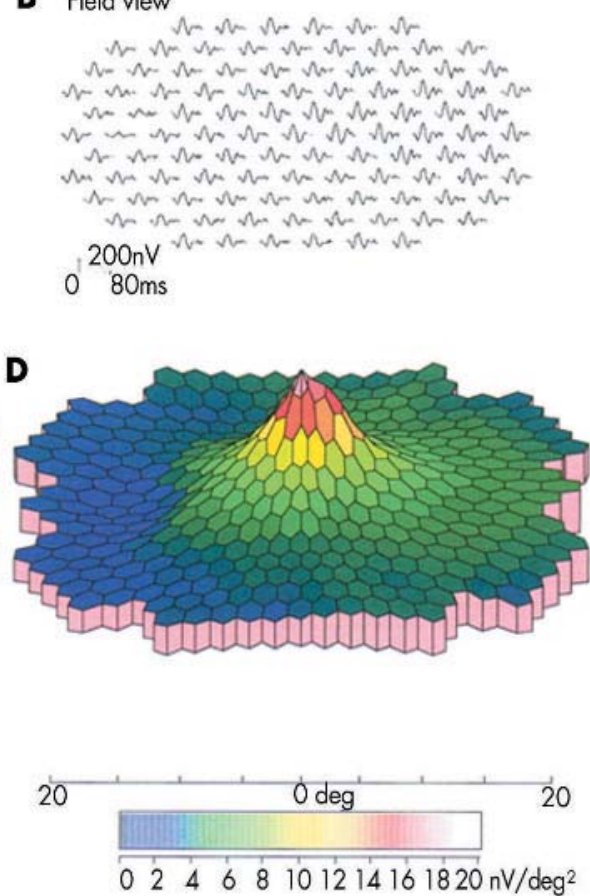

Figure 5 Trace arrays of the right eye (A) and left eye (B) showing decreased amplitudes more in the central region of both eyes. The three dimensional topography map shows blunted foveal peaks in the right eye $(C)$ and left eye (D) 
A Field view

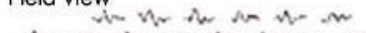

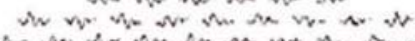

$x^{2} x^{2} x^{2}$

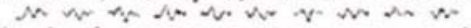

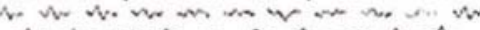

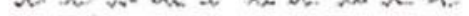

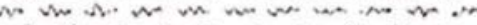

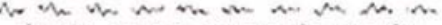

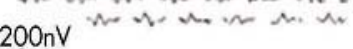

$0 \quad 80 \mathrm{~ms}$

Total response:

$3.02 \mathrm{nV} / \mathrm{deg}^{2}$

c
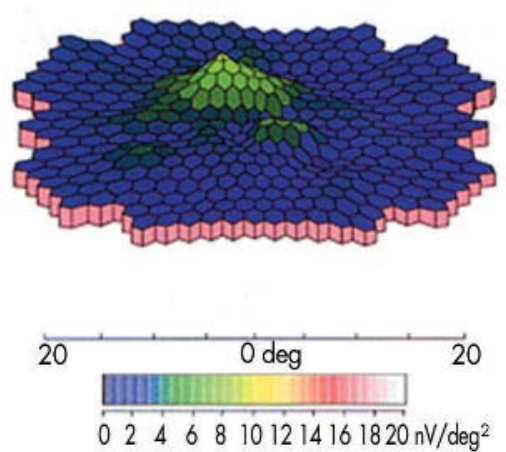

B Field view

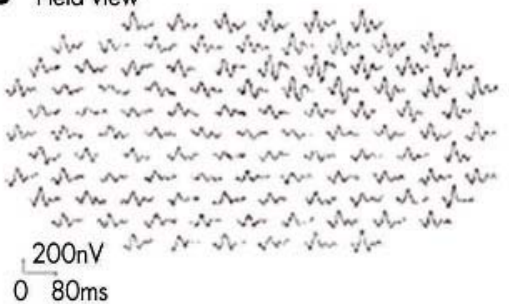

Total response:

$4.57 \mathrm{nV} / \mathrm{deg}^{2}$

\section{D}

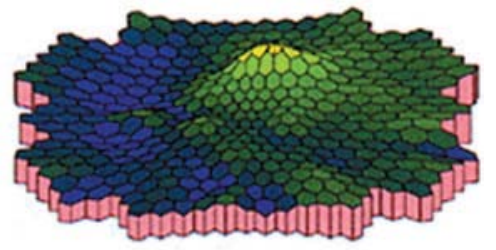

20

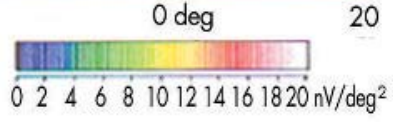

Figure 6 Decreased amplitudes in the central region of the right eye $(A)$ and left eye (B). The three dimensional

topography map shows blunting of the foveal peaks in both eyes. (C) Right eye, (D) left eye. (first positive peak); amplitudes Nl (from baseline to the trough of the first negative wave), Pl (from baseline to the peak of the first positive way), and N1-Pl (from the first negative trough to the first positive peak). The responses elicited by the central six hexagons were summated and designated as ring 1 (central 7 degrees, foveal and parafoveal); and the responses from another concentric ring of 16 hexagons were also summated and designated ring 2 (central 10-12 degrees, parafoveal). Because we were looking for a retinal dysfunction in the macular region, we limited the analysis to the responses elicited in those two rings (fig 8). The N1, Pl latencies and the Nl-Pl, Nl, and Pl amplitudes of both eyes were averaged. These were then compared in the ethambutol treated patients to 10 control subjects (six
A Field view

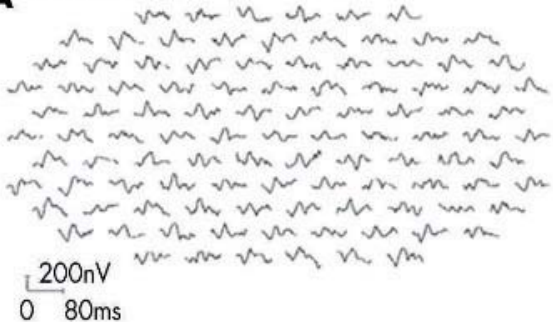

Total response:

$3.10 \mathrm{nV} / \mathrm{deg}^{2}$

C

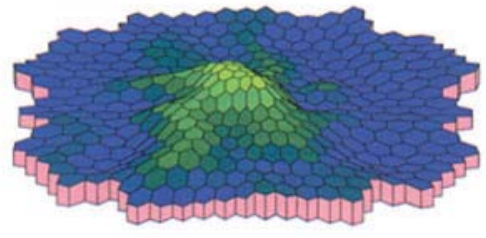

20

0 deg

20

$02468101214161820 \mathrm{nV} / \mathrm{deg}^{2}$
B Field view

$\sim \sim \sim m$ ros

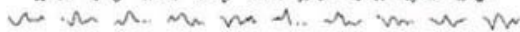

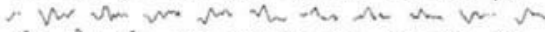

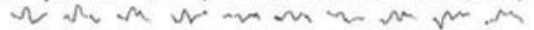

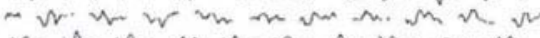

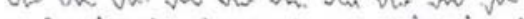

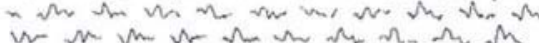

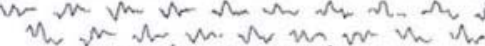
$200 n V$

$0 \quad 80 \mathrm{~ms}$

Total response:

$3.25 \mathrm{nV} / \mathrm{deg}^{2}$

D
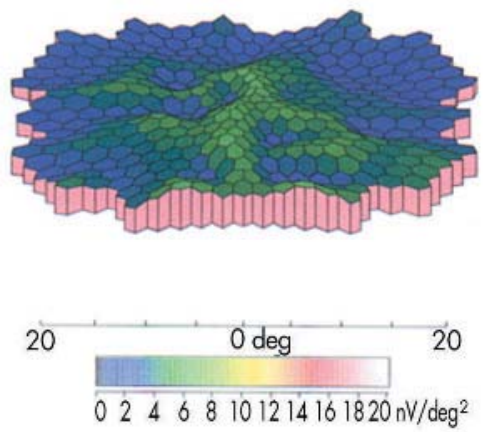

Figure 7 Four months after the first $m E R G$. The amplitudes are still diminished centrally in both $(A)$ right eye and (B) left eye. The three dimensional map still shows blunting of the foveal peaks. (C) Right eye, (D) left eye. 
Stimulus name: Hexagon 103

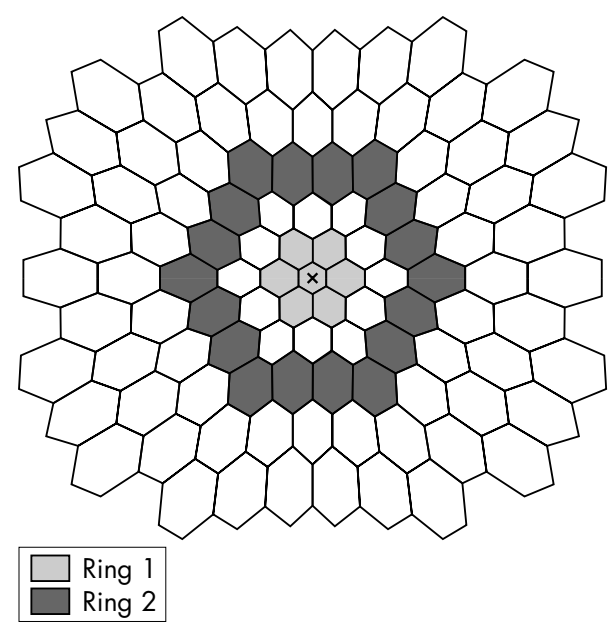

Figure 8 Diagram showing the two rings we tested with Veris 4.8. Ring 1 comprises the six central hexagons in the central 7 degrees, while ring 2 comprises 16 hexagons located 10-12 degrees from the centre.

women and four men) with a mean age of 61.5 (SD 5.75) years using the non-parametric Wilcoxon rank sum test. There was no statistically significant difference between the mean age of the control group and the ethambutol treated patients $(p=0.14)$. Each one of the control group subjects had a visual acuity of 20/30 or better in one or both eye, and a normal neuro-ophthalmic assessment. In addition, none of the control group subjects was taking any medications that could adversely affect retinal function

\section{RESULTS}

The mean $\mathrm{Nl}$ amplitude in ring $\mathrm{l}$ was significantly lower in the ethambutol treated patients than the control group (3.20 versus $9.25 \mathrm{nV} /$ degree $\left.^{2}\right)(\mathrm{p}<0.05)$ (fig 9). The mean Nl-Pl amplitudes, $\mathrm{Pl}$ amplitudes, and the mean $\mathrm{Nl}$ and $\mathrm{Pl}$ latencies in ring 1 were not significantly lower in the ethambutol treated patients compared to the control groups (table 1). There was no significant difference in any of the latencies and the amplitudes in ring 2 between the ethambutol treated patients and the control group (table 2).

\section{DISCUSSION}

We have demonstrated mERG abnormalities in patients with presumed ethambutol optic neuropathy. These changes are characterised by a decrease in amplitude with predilection for

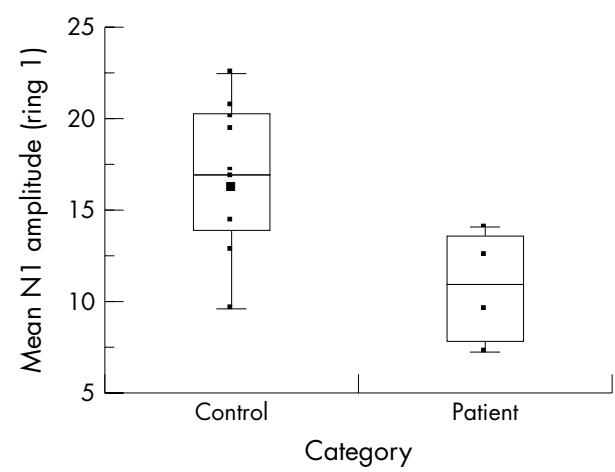

Figure 9 A box plot diagram showing the difference in the mean N1 amplitude in the ethambutol treated patients and the control group. Mean amplitude in $\mathrm{nV} / \mathrm{deg}^{2}$ the central areas (macula). Previous studies have found abnormalities in the visual evoked potentials, ${ }^{9}$ full field ERG and EOG in patients with presumed ethambutol optic neuropathy. ${ }^{10-12}$ In experiments on fish, ethambutol altered synaptic connections between horizontal cells and cones in a dose related fashion, resulting in degeneration of the cone pedicles. $^{13}$

In our study, the $\mathrm{Nl}$ amplitude was found to be significantly lower in the ethambutol treated patients compared to age matched controls. The source of the multifocal ERG signals, as in full field ERG, is thought to be from the outer retina with very little contribution from the inner retina (ganglion cell layer)..$^{14}$ Therefore, for a disease to decrease the amplitude of the mERG, the cone photoreceptors or cone driven bipolar cells must be abnormal. Although there was a statistically significant difference only between the $\mathrm{Nl}$ amplitude of the patients and control subjects, it is possible that our patient group comprised patients in various stages of ethambutol toxicity. In fact, when we compared the N1-P1, and Pl amplitudes of patients 2 and 4 (advanced toxicity) with the control group, they were significantly lower $(\mathrm{p}=<0.05)$. These two patients, however, were also older than patients 1 and 3 . It still is possible though that given enough time, Nl-Pl and Pl amplitudes would eventually be affected in the other patients.

Because of the small sample size of this study, it is difficult to reach a definite conclusion about our observations. Although an abnormal mERG can be caused by eccentric fixation, either voluntary (functional visual loss) or because of a small central visual field loss caused by optic atrophy, fixation was meticulously monitored during testing in all patients.

With the resurgence of tuberculosis, especially in the immunocompromised group, and the increasing reports of MAC pulmonary infections even in immunocompetent ${ }^{16} 17$ and elderly women with no predisposing factors, ${ }^{18}$ prompt diagnosing of ethambutol toxicity can be important in preventing permanent visual loss. We believe our findings merit re-examining the widely accepted notion that ethambutol causes primarily optic neuropathy. Future studies with a larger sample size are needed to determine the early stages and the natural history of retinal toxicity caused by ethambutol.

\section{Authors' affiliations}

R S Behbehani, R C Sergott, P J Savino, Neuroophthalmology Service, Wills Eye Hospital, Jefferson Medical College, Thomas Jefferson University, Philadelphia, PA, USA

E L Affel, Visual Physiology Department, Wills Eye Hospital, Jefferson Medical College, Thomas Jefferson University, Philadelphia, PA, USA

The authors have no proprietary interest in any of the instruments used or any other aspect of this study.

Correspondence to: Raed Behbehani, MD, Neuro-ophthalmology Service, Wills Eye Hospital, 840 Walnut Street, Philadelphia, PA 19107, USA; r_behbehani@hotmail.com

Accepted for publication 1 February 2005

\section{REFERENCES}

1 Carr RE, Henkind P. Ocular manifestations of ethambutol. Arch Ophthalmol 1962;67:566-71.

2 Barron GJ, Tepper L, lovine G. Ocular toxicity from ethambutol. Am J Ophthalmol 1974;77:256-60.

3 Joubert PH, Strobele JG, Ogle CW, et al. Subclinical impairment of colour vision in patients receiving ethambutol. Br J Clin Pharmacol 1986;21:213-6.

4 Arruga J. Subjective color desaturation test in the diagnosis of the effects of ethambutol on the anterior optic pathway. Bull Soc Ophtalmol Fr 1982;82:189-92.

5 Choi SY, Hwang JM. Optic neuropathy associated with ethambutol in Koreans. Korean J Ophthalmol 1997;1 1:106-10. 
6 Kuumar A, Sandramouli S, Verma L, et al. Ocular ethambutol toxicity: is it reversible? J Clin Neuro-ophthalmol 1993;13:15-17

7 Alvarez KL, Krop LC. Ethambutol-induced ocular toxicity revisited. Ann Pharmacother 1993;27:102-3.

8 Lessell S. Toxic and deficiency optic neuropathies. In: Smith JL, Glaser JS, eds. Neuro-ophthalmology symposium of the University of Miami and the Bascom Palmer Eye Institute, Vol 7. St Louis: CV Mosby, 1973:21-37.

9 Yiannkias C, Walsh JC, McLeod JG. Visual evoked potentials in the detection of subclinical optic toxic effects secondary to ethambutol. Arch Neurol 1983:40:645-8

10 Hennekes R. Clinical ERG findings in ethambutol intoxication. Graefes Arch Clin Exp Ophthalmol 1982;218:319-21.

11 Kakisu Y, Adachi-Usami E, Mizota A. Pattern electroretinogram and visua evoked cortical potential in ethambutol optic neuropathy. Doc Ophthalmol 1987:67:327-34.

12 Yen MY, Wang AG, Chiang SC, et al. Ethambutol retinal toxicity: an electrophysiologic study. J Formos Med Assoc 2000;99:630-4.
13 Kohler K, Zrenner E, Weiler R. Ethambutol alters spinule-type synaptic connections and induces morphologic alterations in the cone pedicles of the fish retina. Invest Ophthalmol Vis Sci 1995;36:1046-55

14 Marmor MF, Hood DC, Keating D, et al. Guidelines for basic multifocal electroretinography (mffERG). Doc Ophthalmol 2003:106:105-15.

15 Hood DC, Odel JG, Chen CS, et al. The multifocal electroretinogram. J Neuroophthalmol 2003;23:225-35.

16 Bux-Gewher I, Hagan HP, Rusch Gerdes S, et al. Fatal pulmonary infection with Mycobacterium celatum in an apparently immnunocompetent patient. $J$ Clin Microbiol 1998:36:586-9.

17 Tjhie JHT, Van Belle AF, Dessens-Kroons M, et al. Misidentification and diagnostic delay caused by false positive amplified Mycobacterium tuberculosis direct test in an immunocompetent patient with mycobacterium celatum infection. J Clin Microbiol 2001:39:2311-2.

18 Prince DS, Peterson DD, Steiner RM, et al. Infection with Mycobacterium avium complex in patients without predisposing conditions. N Engl J Med 1989;321:863-8.

\section{Clinical Evidence-Call for contributors}

Clinical Evidence is a regularly updated evidence-based journal available worldwide both as a paper version and on the internet. Clinical Evidence needs to recruit a number of new contributors. Contributors are healthcare professionals or epidemiologists with experience in evidence-based medicine and the ability to write in a concise and structured way.

Areas for which we are currently seeking authors:

- Child health: nocturnal enuresis

- Eye disorders: bacterial conjunctivitis

- Male health: prostate cancer (metastatic)

- Women's health: pre-menstrual syndrome; pyelonephritis in non-pregnant women

However, we are always looking for others, so do not let this list discourage you.

Being a contributor involves:

- Selecting from a validated, screened search (performed by in-house Information Specialists) epidemiologically sound studies for inclusion.

- Documenting your decisions about which studies to include on an inclusion and exclusion form, which we keep on file.

- Writing the text to a highly structured template (about 1500-3000 words), using evidence from the final studies chosen, within 8-10 weeks of receiving the literature search.

- Working with Clinical Evidence editors to ensure that the final text meets epidemiological and style standards.

- Updating the text every six months using any new, sound evidence that becomes available. The Clinical Evidence in-house team will conduct the searches for contributors; your task is simply to filter out high quality studies and incorporate them in the existing text.

- To expand the topic to include a new question about once every 12-18 months.

If you would like to become a contributor for Clinical Evidence or require more information about what this involves please send your contact details and a copy of your CV, clearly stating the clinical area you are interested in, to Klara Brunnhuber (kbrunnhuber@ bmigroup.com).

\section{Call for peer reviewers}

Clinical Evidence also needs to recruit a number of new peer reviewers specifically with an interest in the clinical areas stated above, and also others related to general practice. Peer reviewers are healthcare professionals or epidemiologists with experience in evidence-based medicine. As a peer reviewer you would be asked for your views on the clinical relevance, validity, and accessibility of specific topics within the journal, and their usefulness to the intended audience (international generalists and healthcare professionals, possibly with limited statistical knowledge). Topics are usually 1500-3000 words in length and we would ask you to review between 2-5 topics per year. The peer review process takes place throughout the year, and our turnaround time for each review is ideally 10-14 days.

If you are interested in becoming a peer reviewer for Clinical Evidence, please complete the peer review questionnaire at www.clinicalevidence.com or contact Klara Brunnhuber (kbrunnhuber@bmigroup.com). 